\title{
Cell cycle-dependent expression and subcellular localization of fructose 1,6-bisphosphatase
}

\author{
Piotr Mamczur • Agnieszka Joanna Sok • \\ Adam Rzechonek $\cdot$ Dariusz Rakus
}

Accepted: 26 October 2011 / Published online: 6 November 2011

(C) The Author(s) 2011. This article is published with open access at Springerlink.com

\begin{abstract}
Recently a gluconeogenic enzyme was discovered-fructose 1,6-bisphosphatase (FBPase) - that localizes in the nucleus of a proliferating cell, but its physiological role in this compartment remains unclear. Here, we demonstrate the link between nuclear localization of FBPase and the cell cycle progression. Results of our studies indicate that in human and mouse squamous cell lung cancer, as well as in the HL-1 cardiomyocytes, FBPase nuclear localization correlates with nuclear localization of $\mathrm{S}$ and G2 phase cyclins. Additionally, activity and expression of the enzyme depends on cell cycle stages. Identification of FBPase interacting partners with mass spectrometry reveals a set of nuclear proteins involved in cell cycle regulation, mRNA processing and in stabilization of genomic DNA structure. To our knowledge, this is the first experimental evidence that muscle FBPase is involved in cell cycle events.
\end{abstract}

Keywords FBPase - Cyclins - KLN-205 .

Squamous cell lung cancer $\cdot$ HL-1

Electronic supplementary material The online version of this article (doi:10.1007/s00418-011-0884-1) contains supplementary material, which is available to authorized users.

P. Mamczur · A. J. Sok · D. Rakus $(\bowtie)$

Department of Animal Molecular Physiology,

Institute of Zoology, Wroclaw University, Cybulskiego 30,

50-205 Wrocław, Poland

e-mail: drakus@biol.uni.wroc.pl

A. Rzechonek

Department of Thoracic Surgery, Lower Silesian Pulmonary

Center, Grabiszynska 105, 50-439 Wrocław, Poland

\section{Introduction}

Fructose 1,6-bisphosphatase (FBPase; EC 3.1.3.11) catalyzes irreversible hydrolysis of fructose-1,6-bisphosphate to fructose-6-phosphate and inorganic phosphate (Gomori 1943). Genetic and kinetic studies have revealed that at least two isozymes of FBPase exist in vertebrates: the liver isozyme (FBP1) - a regulatory enzyme of gluconeogenesis, and the muscle isozyme (FBP2), which participates in glycogen synthesis from carbohydrate precursors. Unfortunately, the physiological role of FBP2 is not yet fully understood (Gleeson 1996; Gomori 1943; Tejwani 1983; Tillmann et al. 2002). In contrast to the liver isozyme, the muscle FBPase is expressed widely and even in non-gluconeogenic cells (Al-Robaiy and Eschrich 1999). The role for FBP2 in these cells remains unclear, but a growing body of evidence suggests that the physiological function of the muscle isozyme goes beyond participation in the synthesis of glucose/glycogen from non-carbohydrate substrates (Gizak et al. 2006, 2009).

Both FBPase genes are expressed in cancer cells; however, the level of their expression is presumably reduced in comparison with non-malignant tissues (Bigl et al. 2008; Liu et al. 2010). It has been hypothesized that downregulation of FBP1 in gastric cancer cells contributes to the Warburg effect and might be attributed to the cells' growth and proliferation (Liu et al. 2010).

Our previous studies demonstrated that in some types of cells, FBPase is located inside the nuclei and we suggested that such localization of the enzyme accompanies the cells' potential to divide. We also presented evidence that in cardiomyocytes, FBPase disappeared from the nuclei after disruption of $\beta_{1}$-adrenergic and phosphoinositide 3-kinase signalling pathway, which coincided with a significant increase in cardiomyocyte mortality (Gizak et al. 2009). Based on these results, we now ask whether subcellular 
localization of FBPase and expression levels of the enzyme are related to the cell cycle stages/phases.

To address this issue we investigated cell cycle-dependent changes in expression and subcellular distribution of the muscle FBPase isozyme in human squamous cell lung cancer (SCC), in the mouse SCC cell line (KLN-205) and in mouse cardiomyocytes (the HL-1 cell line). To the best of our knowledge, the data presented here provide the first experimental evidence that FBPase expression and nuclear localization oscillates in a cell cycle-dependent manner. Results of our studies also demonstrate that FBP2 interacts in vitro with a set of nuclear proteins involved in RNA processing, nucleosome assembly and cell cycle regulation.

Our results yielded novel insight into mechanisms of cell cycle regulation and might provide new approaches in cancer treatment.

\section{Materials and methods}

Mouse squamous cell carcinoma cell line (KLN-205) was obtained from ECACC (Sigma-Aldrich). The HL-1 cardiomyocytes were a gift from Dr. W.C. Claycomb (Louisiana State University Health Science Center, New Orleans, LA, USA), who first established and characterized the cell line (Claycomb et al. 1998).

Histopathologically proven human squamous cell lung cancer (SCC) samples were removed surgically from patients of the Lower Silesian Pulmonary Center. The samples were taken in accordance with the rules of The Scientific Research Ethical Committee.

Polyester wax was from Science Services. Anti-Ki-67 immunoglobulins (NCL-Ki-67p) were from Biokom and monoclonal antibodies to Cyclin E (CycE) were from Acris Antibodies $\mathrm{GmbH}$. PageRuler ${ }^{\mathrm{TM}}$ Prestained Protein Ladder was obtained from Fermentas-Life Sciences. Western$\operatorname{Dot}^{\mathrm{TM}} 625$ Goat Anti-Rabbit Western Blot Kit was from Invitrogen. All other reagents were from Sigma-Aldrich and were of the cell culture grade.

Rabbit muscle FBPase was isolated according to Rakus and Dzugaj (2000). Rabbit polyclonal antiserum against muscle FBPase was produced as described previously by Gizak and Dzugaj (2003). The antiserum was purified using protein A-agarose gel chromatography according to manufacturer's procedure (HiTrap Protein A HP, GE Healthcare). The specificity of the immunoglobulins against FBPase was confirmed by immunoblotting and preabsorption experiments (Supplementary Material).

\section{Cell culture}

All cell lines were cultured at $37^{\circ} \mathrm{C}$ in a humidified atmosphere with $5 \% \mathrm{CO}_{2}$ and maintained using standard tissue culture techniques. The HL- 1 cells were handled as previously described (White et al. 2004). The KLN-205 cells were cultured in Eagle's Minimum Essential Medium supplemented with $2 \mathrm{mM}$ glutamine, $1 \%$ non-essential amino acids, penicillin $(100 \mathrm{U} / \mathrm{ml})$, streptomycin $(0.1 \mathrm{mg} / \mathrm{ml})$ and $10 \%$ fetal bovine serum (FBS). The cells were seeded at an initial density of $3 \times 10^{3}$ cells $/ \mathrm{cm}^{2}$ and cultured for 15-144 h. For serum starvation experiments, the KLN-205 cells were grown in the presence of FBS for 2 days and were then maintained in serum-free conditions for 5 days. To achieve cell culture synchronization, the serum-starved cells were stimulated to proliferation by addition of $10 \%$ FBS.

To block $S$ phase entrance, the cells were incubated for $24 \mathrm{~h}$ with 10 or $100 \mu \mathrm{g} / \mathrm{ml}$ concanavalin A (ConA) (Desrivières et al. 1997). The synchronization of cultures at $S$ phase was achieved by incubation of the cells with $1 \mu \mathrm{g} / \mathrm{ml}$ aphidicolin (APC) for $24 \mathrm{~h}$ (Seo et al. 2000).

\section{Activity measurement}

FBPase activity was assayed spectrophotometrically as described previously (Rakus and Dzugaj 2000). One unit of enzyme activity is defined as the amount of the enzyme that catalyzes the formation of $1 \mu \mathrm{mol}$ of product per minute. Protein concentrations were determined using Bradford Reagent (Fermentas). All spectrophotometric measurements were performed with an Agilent 8453 diode array spectrophotometer. Preparation of cellular extract for enzyme activity determination is described in Supplementary Material.

\section{Immunochemistry}

The samples of SCC were fixed in Carnoy's fluid (overnight at $4^{\circ} \mathrm{C}$ ), dehydrated and embedded in polyester wax. Before immunostaining, dewaxed cancer sections were treated using a high-temperature antigen retrieval method (Bankfalvi et al. 1994). The HL-1 and the KLN-205 cells were fixed in $4 \%$ paraformaldehyde for $15 \mathrm{~min}$ at room temperature (RT), washed with PBS, permeabilized with $0.3 \%$ Triton X-100/PBS, and used for immunocytochemical staining.

To study the localization of CycA and CycD1 with FBPase in SCC, the samples were treated as previously described (Mamczur et al. 2010). Tissue sections were incubated (overnight at $4^{\circ} \mathrm{C}$ ) with rabbit polyclonal antiFBPase antibodies $(50 \mu \mathrm{g} / \mathrm{ml})$ and either with mouse monoclonal anti-cyclin A (1:50) or mouse anti-cyclin D1 (1:50) immunoglobulins, followed by the incubation (30 min at RT) with fluorophore-labeled secondary antibodies: goat anti-rabbit-TRITC (1:400) and goat anti-mouse-FITC (1:500). The tissue sections were counterstained with DAPI (0.5 $\mu \mathrm{g} / \mathrm{ml}, 5 \mathrm{~min}, \mathrm{RT})$. 
To check the coexistence of FBPase and $\mathrm{CycE}$ or $\mathrm{CycB} 1$, the human tumor sections were incubated (overnight at $\left.4^{\circ} \mathrm{C}\right)$ with polyclonal anti-FBPase $(50 \mu \mathrm{g} / \mathrm{ml})$ and mouse monoclonal anti-cyclin E (1:25) or rabbit polyclonal anti-cyclin B1 (1:50) immunoglobulins. After incubation with goat anti-rabbit alkaline phosphatase-conjugated (1:500) and goat anti-mouse peroxidase-conjugated $(1: 2,000)$ antibodies, the tissue sections were treated with Fast Red TR/ Naphthol and 3,3'-diaminobenzidine to visualize FBPase and cyclins.

To determine the subcellular localization of the cell cycle markers and FBPase in cultures, the cells were incubated overnight at $4^{\circ} \mathrm{C}$ with rabbit polyclonal anti-FBPase $(50 \mu \mathrm{g} / \mathrm{ml})$ or mouse polyclonal anti-FBPase $(100 \mu \mathrm{g} / \mathrm{ml})$ antibodies and with rabbit polyclonal anti-cyclin B1 (1:500), mouse polyclonal anti-cyclin E (1:25), rabbit polyclonal antiKi-67 (1:1,000) or mouse monoclonal anti-cyclin A (1:100) antibodies. Subsequently, the cultures were incubated with fluorophore-labeled secondary antibodies: goat anti-rabbitFITC (1:2,000) and goat anti-mouse-TRITC (1:2,000). Cell cultures were counterstained with DAPI to visualize the nuclei.

In all of the above immunochemical experiments, the excess of primary and secondary antibodies were removed by intensive washings with $0.1 \%$ Triton X-100/PBS. Endogenous peroxidase activity was blocked by incubation of the sections with $3 \% \mathrm{H}_{2} \mathrm{O}_{2}$ for $1 \mathrm{~h}$ at $\mathrm{RT}$. To avoid the unspecific binding of immunoglobulins, the sections and the cells were incubated with 5\% BSA in PBS for $1 \mathrm{~h}$ at RT before the application of the primary antibodies. All secondary antibodies were diluted in PBS containing $0.5 \%$ BSA. In control reactions the primary antibodies were omitted. The nuclear coexistence of proteins was examined with an Olympus IX71 fluorescence microscope equipped with Cell^F software (Olympus Soft Imaging Solutions $\mathrm{GmbH}$ ) and/or an Olympus FV1000 confocal microscope.

\section{Flow cytometry}

For Flow cytometry (FC) analysis the KLN-205 cells were trypsinized and suspended in PBS $\left(2.5 \times 10^{6}\right.$ cells $/ \mathrm{ml}$ PBS). Then, 2-4 drops of $70 \%$ ethanol (ice cold) were added to the suspension and the cells were gently mixed and centrifuged $\left(5 \mathrm{~min}, 500 \mathrm{~g}, 4^{\circ} \mathrm{C}\right)$. The pellet was re-suspended and fixed in ice cold $70 \%$ ethanol for $15 \mathrm{~min}$. The cells were pelleted by centrifugation $\left(5 \mathrm{~min}, 700 \mathrm{~g}, 4^{\circ} \mathrm{C}\right)$, permeabilized with $0.3 \%$ Triton $\mathrm{X}-100$ in PBS (15 min, RT) and washed with PBS (10 min, RT). Subsequently, the cells were treated with RNAse I (100 $\mu \mathrm{g} / \mathrm{ml}, 30 \mathrm{~min}, \mathrm{RT})$ and DNA was stained with propidium iodide $(50 \mu \mathrm{g} / \mathrm{ml}$, $5 \mathrm{~min}, 37^{\circ} \mathrm{C}$ ). Finally, the cells were washed with PBS and the analysis was carried out using a BD FACSCalibur flow cytometer and WinMDI version 2.9 software.
Fluorescence in situ hybridization

5'-end FITC-labeled oligonucleotides:

\section{oligo-1: (FITC)-5'-TGTCACATTCACGCTCCCCGAA ATCCCATA CAGGTTGGCC oligo-2: (FITC)-5'-CTCACTGCCATCCTCGGGGAAT TTCTTTTTCTGTACATAC \\ oligo-3: (FITC)-5'-GGGTACATGAAGATTCCTCCAT AGACCAAGGTGCGATGCA}

were complementary to three different fragments of mRNA sequence for mouse FBP2 (GenBank ID: NM_007994) and synthesized by Sigma-Genosis (Steinheim, Germany). The KLN-205 cells were fixed in ice-cold methanol (15 min.), washed with PBS $(3 \times 10 \mathrm{~min})$, permeabilized with $0.3 \%$ Triton/PBS (15 min, RT), then used in the Fluorescence in situ hybridization (FISH) procedure.

Before hybridization, the KLN-205 cells were washed twice with PBS for $10 \mathrm{~min}$ and sodium citrate buffer (SSC: $150 \mathrm{mM} \mathrm{NaCl}, 15 \mathrm{mM}$ sodium citrate; $\mathrm{pH}$ 7.0, RT) $(3 \times 10 \mathrm{~min})$. Subsequently, the cells were incubated with prehybridization mixture $(50 \%$ formamide, $0.1 \%$ Ficoll400, $0.1 \%$ BSA, $0.1 \%$ polyvinylpyrrolidone, $5 \mathrm{mM}$ EDTA, $250 \mu \mathrm{g} / \mathrm{ml}$ yeast tRNA, $250 \mu \mathrm{g} / \mathrm{ml}$ DNA from salmon testes, $750 \mathrm{mM} \mathrm{NaCl}, 75 \mathrm{mM}$ sodium citrate; $\mathrm{pH}$ 7.0) for $1 \mathrm{~h}$ at RT. Then, the cells were hybridized at $37^{\circ} \mathrm{C}$ for $3 \mathrm{~h}$ in prehybridization mixture with one of three FITC-labeled oligonucleotides $(1-10 \mu \mathrm{g} / \mathrm{ml})$. In the control reaction, the oligonucleotide probe was omitted. After hybridization the cells were washed with SSC $(2 \times 30 \mathrm{~min})$ and examined with fluorescence microscopy (Olympus IX71 fluorescence microscope).

To co-localize FBP2 mRNA with Cyclin A (CycA) we combined FISH with immunofluorescent staining. The KLN-205 cell cultures were fixed in methanol (ice-cold; $15 \mathrm{~min})$, washed with PBS $(2 \times 10 \mathrm{~min})$ and permeabilized in $0.3 \%$ Triton $\mathrm{X}-100 / \mathrm{PBS}$ ( $15 \mathrm{~min}$ ). The nonspecific sites were blocked with $5 \%$ BSA in PBS at RT for $1 \mathrm{~h}$, followed by the incubation with primary antibodies as described above in the Immunochemistry section. Subsequently, the cells were washed with $0.1 \%$ Triton X-100/PBS $(1 \times 5 \mathrm{~min})$ and PBS $(2 \times 5 \mathrm{~min})$ and incubated (for 30 min at RT) with goat anti-mouse-TRITC $(1: 1,000)$. After washings, the cells were postfixed in $4 \%$ paraformaldehyde/ PBS ( 7 min at RT) and subjected to FISH protocol.

\section{ELISA and MTT assays}

The amount of FBPase and the rate of cell proliferation were checked using an enzyme-linked immunosorbent assay (ELISA) and methylthiazolyldiphenyl-tetrazolium bromide (MTT) cell proliferation test, respectively (Parnas and Linial 1998; Spitzer et al. 2006). 
Briefly, the KLN-205 cells were seeded at $3 \times 10^{3}$ cells/ $\mathrm{cm}^{2}$ into 96-well plates and were grown for 72 or $120 \mathrm{~h}$. Afterwards, the cells were subjected to ELISA and MTT tests. For ELISA, the fixed cells were incubated with rabbit anti-FBPase immunoglobulins as described in the "Immunochemistry" section. Finally, the cells were incubated with goat anti-rabbit peroxidase-conjugated antibodies $(1: 30,000 ; 30 \mathrm{~min}$ at RT) and immunoreaction was visualized with 3,3',5,5'-tetramethylbenzidine (TMB; $30 \mathrm{~min}, \mathrm{RT}$ ). The reaction was stopped by $1 \mathrm{M} \mathrm{HCl}$ and the absorbance at $450 \mathrm{~nm}$ was measured with an ELISA reader (Asys UVM340). In the control reaction anti-FBPase immunoglobulins were omitted. For MTT-based assay the cells were cultured with MTT $(0.5 \mathrm{mg} / \mathrm{ml})$ for $4 \mathrm{~h}$ at standard conditions. After removal of medium, formazan crystals were dissolved in acidified isopropanol (1 $\mathrm{M} \mathrm{HCl}$ in isopropanol) and the absorbance was read at $570 \mathrm{~nm}$ (Asys UVM340). The culture medium without cells was used as a negative control.

RNA isolation and real-time quantitative PCR

Total RNA was obtained by phenol/chlorophorm extraction with TRI Reagent (Applied Biosystems) (Chomczynski and Sacchi 1987). First strand cDNA was synthesized using the High-Capacity cDNA Reverse Transcription Kit (Applied Biosystems) according to the manufacturer's instructions. To screen quantity of the expression of FBPase isozymes in KLN-205 cells, mouse FBP1-specific primers (forward 5'-CAGCTGCTGAATTCGCTCTG, reverse 5'-ACATTG GTTGAGCCAGCGATA) and mouse FBP2-specific primers (forward 5'-GACCCTCTGGATGGATCTTCA, reverse 5'-CAGAAGGCTCATCCTCCGT) were used. To normalize qPCR data a pair of RNA polymerase II alpha-specific primers were used (forward 5'-CAAGATGCAAGAGGA GGAAGA, reverse 5'-CACCTTGCTGATCTGCTCGAT). Quantitative PCR was performed using Applied Biosystems 7900HT Fast Real-Time PCR (Applied Biosystems) and SYBR $^{\circledR}$ Green PCR Master Mix (Applied Biosystems) according to the manufacturer's instructions, with slight modification. Briefly, the qPCR cycle conditions were as follows: pre-incubation for $10 \mathrm{~min}$ at $95^{\circ} \mathrm{C}$ followed by 40 cycles, with each cycle including $15 \mathrm{~s}$ at $95^{\circ} \mathrm{C}, 30 \mathrm{~s}$ at $60^{\circ} \mathrm{C}$, and $30 \mathrm{~s}$ at $72^{\circ} \mathrm{C}$.

A negative control lacking cDNA was included in each assay. Amplification was performed for each of the cDNA samples in triplicate and the relative expression ratio was calculated according to the Pfaffl method (Pfaffl 2001).

Affinity chromatography

A Sepharose 4B-FBP2 column was prepared as described previously (Kowalski et al. 2009). Non-histone nuclear proteins were extracted from $12-18 \times 10^{6} \mathrm{KLN}-205$ cells using NXTRACT CelLytic ${ }^{\mathrm{TM}}$ NuCLEAR ${ }^{\mathrm{TM}}$ Extraction Kit (Sigma). Histones and other nuclear proteins, which strongly associate with DNA, were extracted by an additional treatment with a high salt extraction buffer $(10 \mathrm{mM}$ Tris, $0.5 \mathrm{mM}$ EDTA, $0.5 \mathrm{mM}$ PMSF, $2 \mathrm{mM}$ DTT, $2 \mathrm{M}$ $\mathrm{NaCl}, 60 \mathrm{mM} \mathrm{NaF}$; pH 6.7 at $4^{\circ} \mathrm{C}$ ). Binding of nuclear proteins to Sepharose 4B-FBP2 as well as their elution was performed as described previously (Kowalski et al. 2009). Then, the samples were precipitated with TCA and resolved by SDS-PAGE (Supplementary Material). To identify the nuclear proteins interacting with Sepharose 4B-FBP2, the TCA-precipitated samples were analyzed commercially by ESI-MS at the Mass Spectrometry Laboratory (Institute of Biochemistry and Biophysics, Polish Academy of Sciences, Warsaw).

Statistical analysis

The statistical significance of the results was tested using the Student's $t$ test (Statistica; StatSoft). For all statistical analyses, $p<0.05$ was considered as significant. The results were expressed as mean and standard deviation $( \pm \mathrm{SD})$. The percentage of mitotic cells (mitotic index) was determined with DAPI staining. Ki-67 index is defined as a percentage of cells with nuclear localization of Ki-67 antigen as determined by immuofluorescence microscopy.

\section{Results}

Coexistence of FBPase and cell cycle markers in the nuclei of the KLN-205 cells

Simultaneous localization of FBPase and cell cycle-related markers demonstrated the nuclear localization of FBPase in cells displaying strong Cyclin A (CycA)- and Cyclin B1 (CycB1)-related nuclear fluorescence (Fig. 1a). The measurements of nuclear fluorescence for the cyclins and FBPase revealed that an increase of FBPase-related fluorescence correlates with nuclear accumulation of both the cyclins (Fig. 1b, c). Such correlation may suggest that FBPase accumulates in the cells' nuclei in S and G2 phases.

Regarding nuclear coexistence of FBPase and Cyclin E (CycE), we found that about $50 \%$ of the KLN-205 cells with nuclear localization of the cyclin also displayed nuclear localization of FBPase (Fig. 2a, b). CycE is a marker of the G1/S transition; thus, partial nuclear coexistence of FBPase and the cyclin suggests that FBPase is localized in nuclei of the S and G2 phases but not G1.

Unexpectedly, we observed in the nuclei of the KLN205 cells that FBPase partially coexists with Cyclin D1 $(\mathrm{CycD} 1)$, a marker of the G1 phase of the cell cycle (data 
Fig. 1 Localization of FBPase in the KLN-205 cell nuclei in S/G2 phase of the cell cycle. a Immunofluorescent doublelabeling of FBPase and S/G2 or G2/M cyclins (CycA or CycB1, respectively). Arrows indicate the cells with high nuclear FBPase and the cyclin's immunofluorescence. Bar $40 \mu \mathrm{m}$. Relative nuclear fluorescence of CycA (b) and CycB1 (c) in comparison with the FBPase nuclear signal. Each value represents a mean and standard deviation of at least three independent experiments. A $p$ value less than 0.05 was considered as significant a


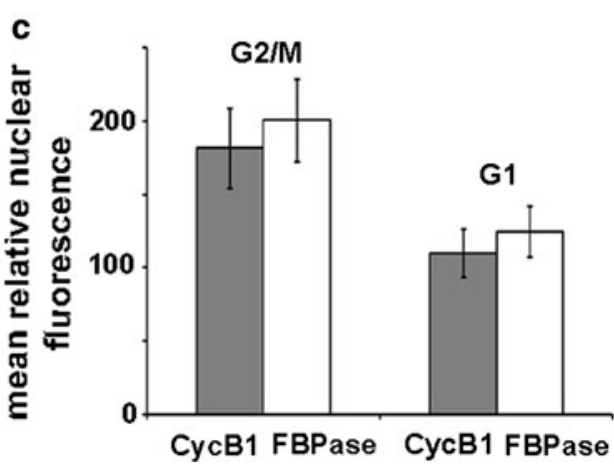

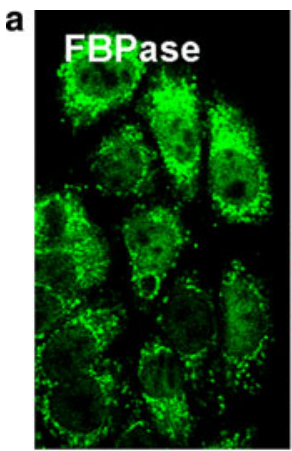
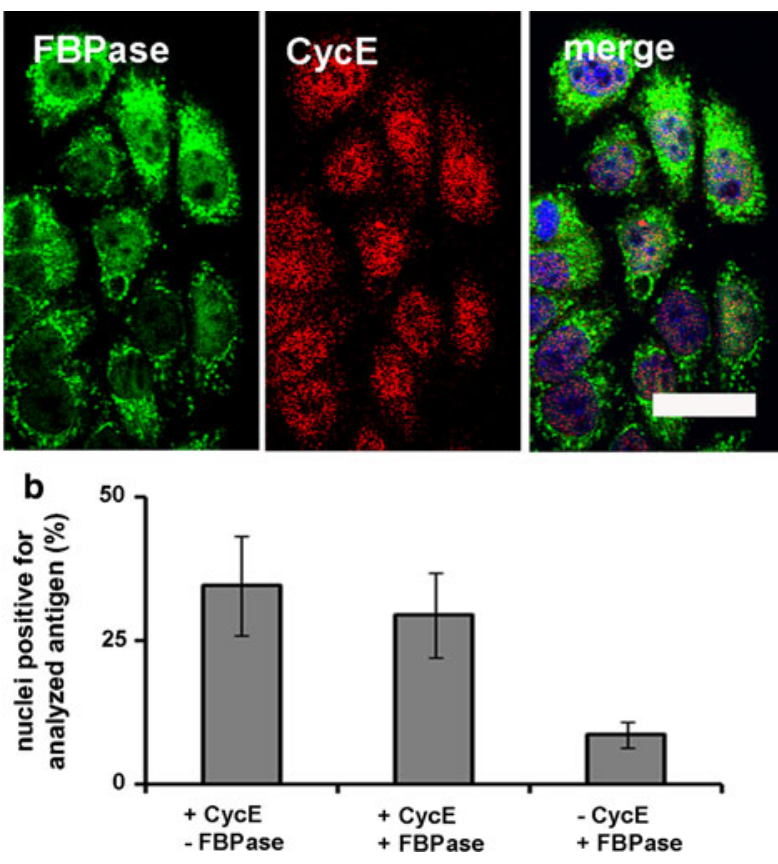

Fig. 2 Coexistence of FBPase and CycE in nuclei of the KLN-205 cells. a Double immunofluorescent staining of FBPase and CycE. b Percentage of nuclear-positive cells for $\mathrm{CycE}$ only, $\mathrm{CycE}$ and FBPase and FBPase only. Bar $20 \mu \mathrm{m}$

not shown). CycD1 is overexpressed in these cells and its concentration and nuclear accumulation were practically unchanged during all stages of cell cycle. The cyclin was present in $96.6 \pm 1.3 \%$ of the KLN-205 cells' nuclei and thus, it cannot be regarded as a cell phase marker in this cell line.

Coexistence of FBPase and cell cycle markers in nuclei of human squamous cell lung cancer

Subcellular co-localization of FBPase with cell cycle markers, cyclins A, B1, D1 and E were studied to establish a relationship between localization of the enzyme and cell cycle events in human squamous cell lung cancer (SCC). We observed (excluding presence in cytoplasm) that FBPase accumulates in nuclei positive for $\mathrm{CycA}$ and $\mathrm{CycB} 1$ (Fig. 3a, d). On the other hand, an entirely cytoplasmic distribution of FBPase correlated with nuclear localization of CycD1 (Fig. 3b). These data confirmed our supposition that nuclear localization of FBPase is related to the $\mathrm{S}$ and $\mathrm{G} 2$ phases of the cell cycle. However, in contrast to the KLN-205 cells, we could not detect FBPase in CycE positive nuclei of human SCC (Fig. 3c).

The effect of cell culture confluence on FBPase localization and expression in the KLN-205 cells

We observed that in the KLN-205 cells, subcellular localization of FBPase depended on the cell culture density (Fig. 4a). An increasing density of the cell culture resulted in a gradual withdrawal of FBPase from the nuclei 
Fig. 3 Nuclear localization of FBPase in different phases of the cell cycle in human squamous cell lung cancer. a Co-localization of CycA and FBPase in nuclei of S/G2 phase cells. b Localization of FBPase and G1 phase marker, $\mathrm{CycD} 1$. c Co-immunostaining for FBPase and CycE, a marker of G1/S transition. Arrows indicate CycE-positive and FBPasenegative cells. d Co-localization of $\mathrm{CycB} 1$ and FBPase. Arrows point to FBPase- and $\mathrm{CycB} 1$ positive nuclei. e Percentage of nuclei positive for $\mathrm{CycA}$, $\mathrm{CycD} 1$ and $\mathrm{CycB} 1$ with respect to subcellular localization of FBPase. In $\mathbf{a}, \mathbf{b}$ and $\mathbf{d}$ the nuclei were counterstained with DAPI. Bar $30 \mu \mathrm{m}$ in $\mathbf{a}, \mathbf{b}$ and $40 \mu \mathrm{m}$ in $\mathbf{c}, \mathbf{d}$ a


b
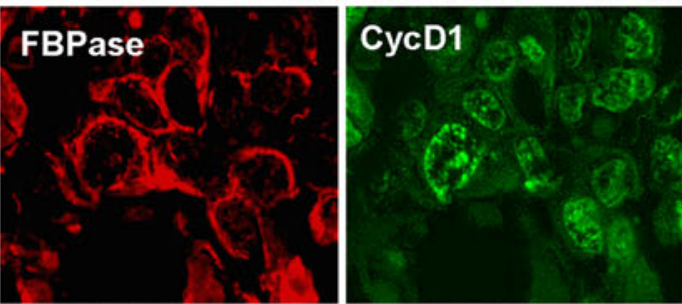

C

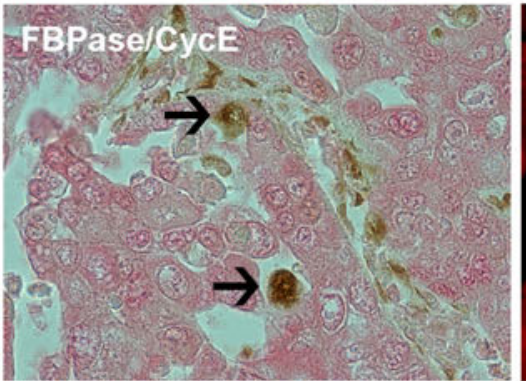

d
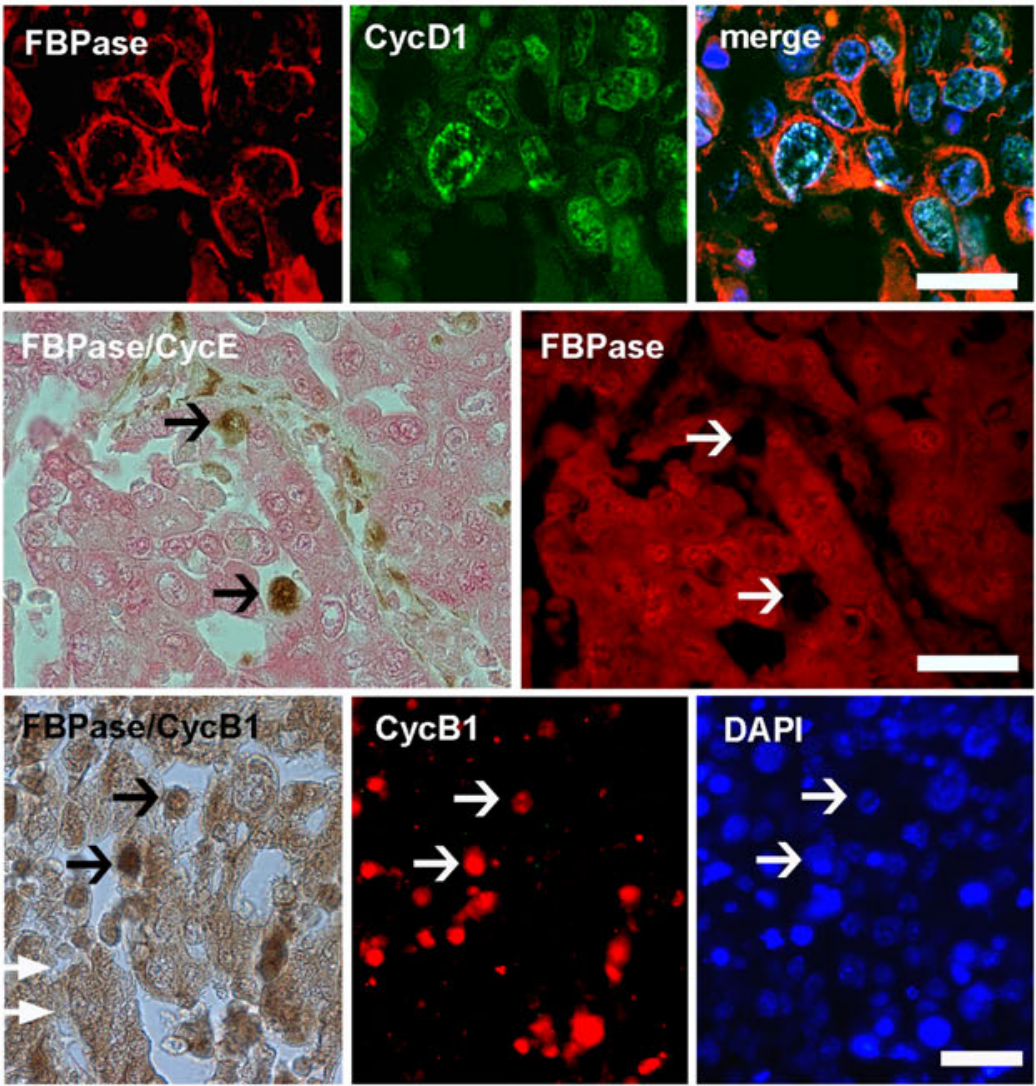

FBPase

(Fig. 4a). The nuclear/cytoplasmic ratio of FBPase-related fluorescence was about twice as long as the mitotic index and is in the range of 3.9-9, but decreased nearly to 1 , while the mitotic index dropped below 2 (Fig. 4d).

Changes in the density of the cell culture also affected FBPase expression. The relative amount of FBPase-as measured using ELISA and expressed as a ratio of TMB to MTT absorbance reflecting the amount of cells-decreased at least twofold with an increasing cell culture density (Fig. 5). To test the hypothesis that the amount of FBPase depends on the rate of cell proliferation, we determined the specific activity, which is a precise method to validate enzyme quantity. Results of our experiment revealed that the FBPase specific activity changes from 6.65 to $0.24 \mathrm{mU} / \mathrm{mg}$ during KLN-205 cell culture growth (Table 1). The highest specific activity was observed during the period of fast growth of the cell culture (Table 1; Fig. 4b). The high density of the cells and the low mitotic index (Fig. 4b, c) correlated with a dramatic decrease of FBPase activity (Table 1).

To verify if the proliferative activity of the KLN-205 cells changes with a rise in density of the cell culture, we measured DNA content using FC (Table 2). As was previously described for other cell lines (Khammanit et al. 2008), we observed that an increasing confluency of the culture correlated with an increase of the G1 and a decrease of the $\mathrm{S}$ and $\mathrm{G} 2 / \mathrm{M}$ phase cells.

Taking into consideration that the amount of FBPase protein decreases during cell culture growth (Fig. 5; Table 1) we tested whether this decrease correlates with changes in expression of mRNA for FBPase. We observed that the KLN-205 cells expressed both liver and muscle FBPase, but the muscle transcript was more predominant. The real-time quantitative PCR (qPCR) analysis revealed a 404 -fold $( \pm 41.5)$ higher amount of mRNA for FBP2 relative to FBP1 mRNA.

The qPCR analysis also revealed that the expression of FBP2 is about twofold lower after $96 \mathrm{~h}$ of cell culture, whereas during the same time period, FBP1 mRNA was slightly elevated in response to cell culture growth (Fig. 6a). Although these changes were minute yet statistically significant, we verified the quantitative PCR (qPCR) results using a FISH approach. The analysis of the FISH signal revealed almost a twofold decrease of mRNA for FBP2 during $96 \mathrm{~h}$ of the cell culture growth (Fig. 7a, b), which agreed with the qPCR analysis. To determine whether the expression of mRNA for FBP2 in the KLN-205 cells depends on cell cycle phases, we localized cyclins with mRNA for muscle FBPase. The results indicated that the elevation of mRNA for FBP2 is correlated with the high expression of CycA (Fig. 7c).

Regarding the subcellular localization of FBPase mRNA, we observed that the mRNA also localized in nucleoli of the KLN-205 cells (Fig. 7; Supplementary Material). This unexpected localization requires further investigation, which is beyond the scope of this manuscript.

The effect of serum withdrawal on FBPase expression and localization in the KLN-205 cells

It is well established that proliferation of cultured cells depends on serum presence in culture medium and that the serum-starvation results in a quiescent, G0-like cell stage (Hayes et al. 2005; Khammanit et al. 2008). The withdrawal of the serum from the KLN-205 cell culture resulted in a 7.4-fold decrease in mitotic and Ki-67 labeling indices (Fig. 8a). Simultaneously, we observed a significant decrease in FBPase immunostaining, both in cells' nuclei and in cytoplasm (Fig. 8b). The effect of serum withdrawal was reversible and re-addition of serum to serum-deprived cells resulted in elevation of the FBPase-related immunofluorescence and in the nuclear accumulation of the enzyme as well as $\mathrm{Ki}-67$ and CycA proteins (Fig. 8c, d).

Unexpectedly, the qPCR analysis demonstrated that serum starvation resulted in significant (approximately tenfold) elevation of both FBPase mRNAs (Fig. 6a). This observed elevation was in apparent contrast to our data showing that serum withdrawal reduces manyfold the activity and the amount of FBPase (Table 1; Fig. 8). Thus, we re-examined the effect of serum starvation on the mRNA expression using a complementary, semi-quantitative approach-FISH. The fluorescence analysis showed nearly a twofold increase of FBPase mRNA-related signal during serum starvation (Fig. 6c), which suggests that FBPase mRNA expression in the G0-like phase cells is elevated. but the enzyme activity is reduced (Table 1).

The effect of aphidicolin, norepinephrine and concanavalin A on FBPase localization in the KLN-205 and the HL-1 cell lines

Supplementation of the culture medium with aphidicolin (APC) - a specific inhibitor of DNA polymerase $\alpha$, results in the synchronization of cells at $\mathrm{S}$ phase (Khammanit et al. 2008; Pedrali-Noy et al. 1982; Seo et al. 2000). In such APC-treated KLN-205 and HL-1 cells, we observed a strong accumulation of FBPase and CycA in cells' nuclei (Fig. 9). Moreover, although it had been previously demonstrated that norepinephrine (NE) stimulation is indispensable for nuclear FBPase retention in the HL-1 cells (Gizak et al. 2009), we found that APC induced nuclear accumulation of the enzyme even in the absence of $\mathrm{NE}$ (Fig. 9).

We observed the opposite effect, the retention of FBPase in cytoplasm, in the ConA-treated KLN-205 cells (Fig. 10). ConA is an agent that prevents cells from 
a

time of

growth

FBPase

DAPI

$15 \mathrm{~h}$
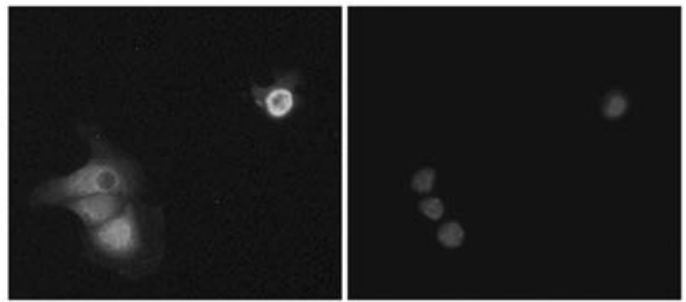

$24 h$
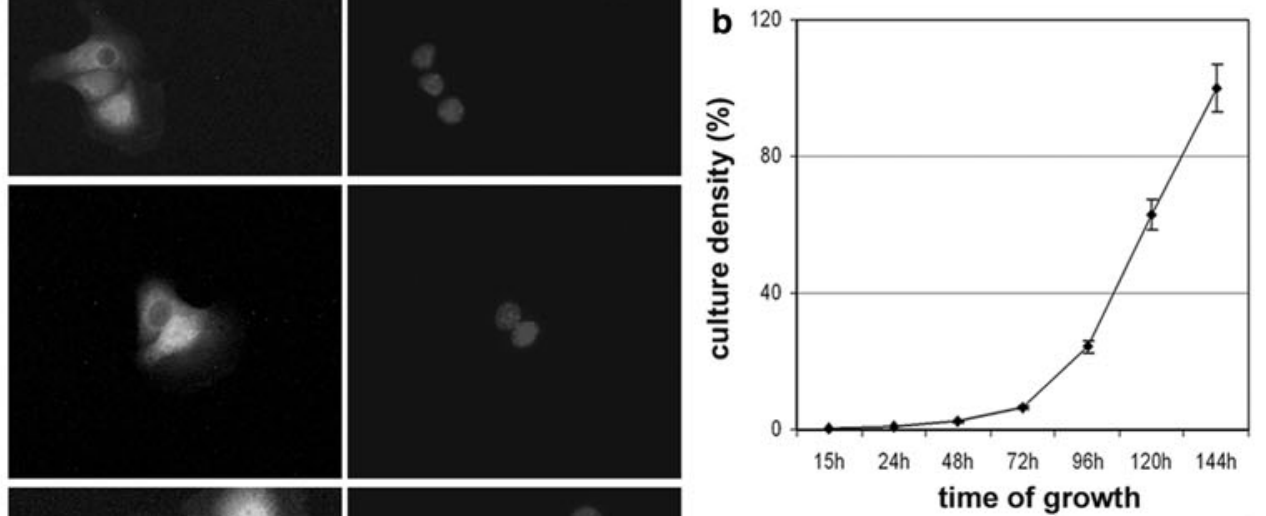

$48 \mathrm{~h}$
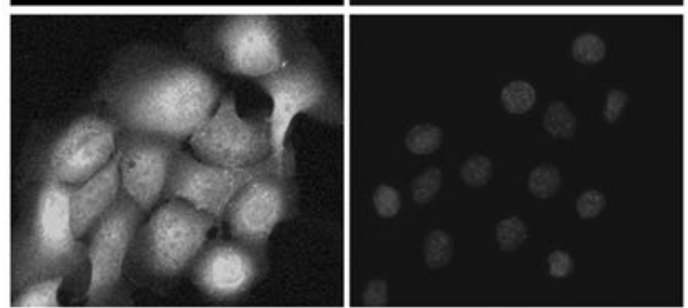

$72 \mathrm{~h}$
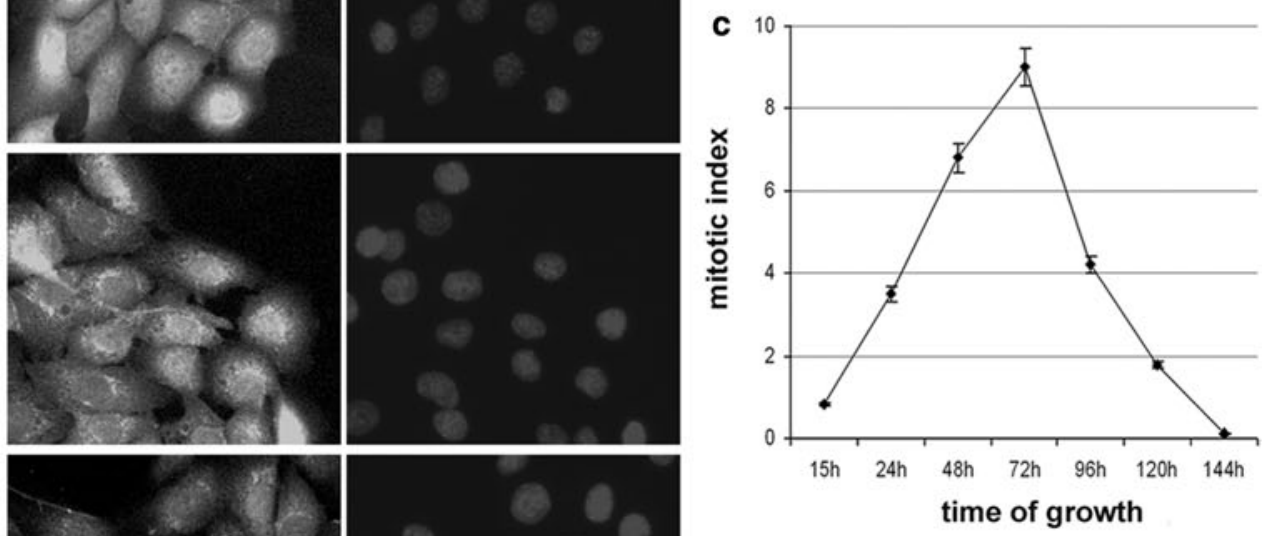

$96 \mathrm{~h}$


$120 \mathrm{~h}$
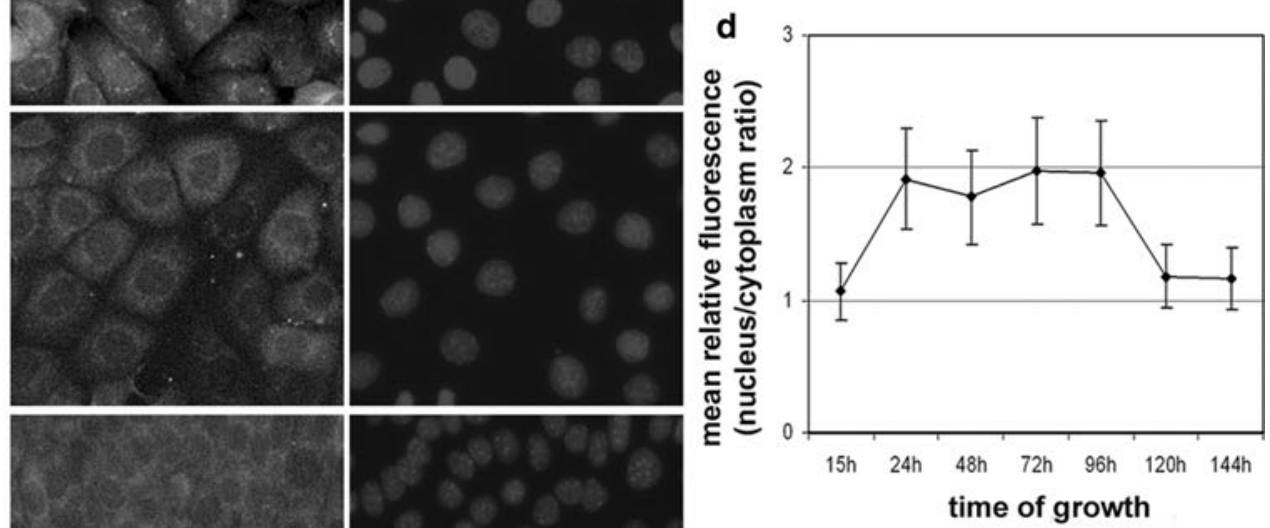

144h

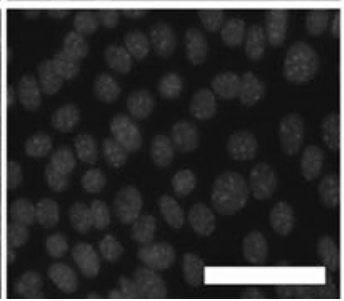

time of growth 
4 Fig. 4 The effect of the KLN-205 cell culture confluence on FBPase localization and mitotic index. a The intensity of FBPase-related immunofluorescent signal and subcellular localization of the enzyme changes during the growth of the cell culture. Scale bar $30 \mu \mathrm{m}$. The changes of culture density (b) and mitotic index (c) during the KLN205 cell culturing. d Variation of FBPase nuclear localization expressed as a nuclear/cytoplasmic immunofluorescence ratio. Each value represents the mean and standard deviation of at least three independent experiments. A $p$ value less than 0.05 was considered as significant

entering into $\mathrm{S}$ phase (G0/G1 block) and inhibits cell cycle progression through the late $\mathrm{G} 2$ phase (G2 block) (Mallucci et al. 1980). Thus, cytoplasmic retention of FBPase in the ConA-treated cells supported the hypothesis that nuclear FBPase is involved in some $\mathrm{S} / \mathrm{G} 2$ phase events.

Identification of nuclear proteins interacting with FBPase

To identify the nuclear proteins in KLN-205 cells that interact with FBPase, we used affinity chromatography and subsequent MS analysis as described in "Materials and methods". We identified several core and linker histones (Table 3) and non-histone nuclear proteins; ribonucleoproteins (RNPs), helicases, lamina-associated polypeptides (thymopoietins) and others that interacted with FBPase (Table 4). Most of these non-histone proteins were previously shown to be involved in interchromatin granule clusters (IGC) formation (Rappsilber et al. 2002; Saitoh et al. 2004), the nuclear structures engaged in transcription and mRNA maturation (Saitoh et al. 2004).

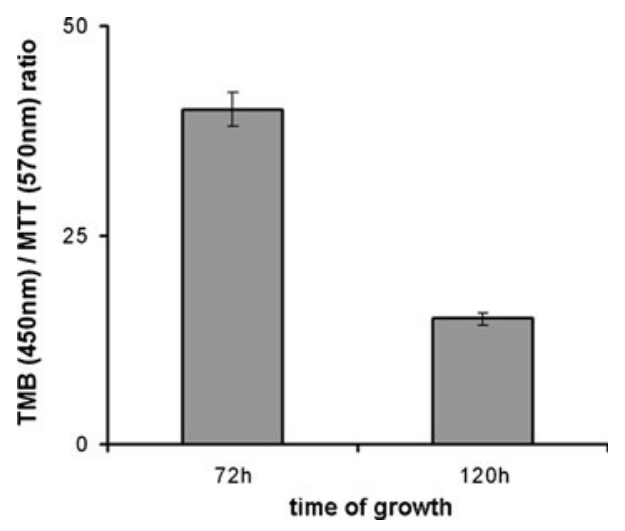

Fig. 5 The effect of the KLN-205 cell culture density on the amount of FBPase. The culture confluence was determined using a MTTbased assay. The amount of FBPase was estimated using ELISA with the secondary antibodies conjugated to peroxidase and detected with TMB. The changes in FBPase amount in response to increasing density of the KLN-205 cell culture were expressed as a TMB/MTT absorbance ratio. The results of three experiments are presented as a mean and $\mathrm{SD} ; p<0.05$
Table 1 The effect of time of the culture growth and serum starvation on FBPase activity in the KLN-205 cells

\begin{tabular}{lll}
\hline & $\begin{array}{l}\text { Time of the } \\
\text { culture growth }\end{array}$ & $\begin{array}{l}\text { FBPase activity } \\
\text { (mU/mg prot.) }\end{array}$ \\
\hline+ Serum & $48 \mathrm{~h}$ & $4.35 \pm 1.3$ \\
& $72 \mathrm{~h}$ & $6.65 \pm 1.1$ \\
& $96 \mathrm{~h}$ & $0.41 \pm 0.1$ \\
& $120 \mathrm{~h}$ & $0.24 \pm 0.1$ \\
- Serum $^{\mathrm{a}}$ & ${ }^{\mathrm{a}}$ & Undetectable
\end{tabular}

Data are demonstrated as mean $\pm \mathrm{SD}$

a See "Materials and methods" section for the details of cell culture conditions

Table 2 The effect of time of the culture growth on the percentage of the KLN-205 cells in particular cell cycle phases as determined by flow cytometry DNA measurements

\begin{tabular}{lrr}
\hline Cell cycle phases & \multicolumn{2}{l}{ Time of the culture growth } \\
\cline { 2 - 3 } $72 \mathrm{~h}$ & \multicolumn{1}{l}{$120 \mathrm{~h}$} \\
\hline G1 (\%) & $47 \pm 4.6$ & $56.4 \pm 0.7$ \\
$\mathrm{~S}+\mathrm{G} 2 / \mathrm{M}(\%)$ & $49.3 \pm 3.5$ & $39.7 \pm 4.3$ \\
\hline
\end{tabular}

Data are reported as mean \pm SD of three independent experiments; $p<0.05$ was considered as significant

The lack of cytoplasmic proteins known to associate with FBPase (e.g., aldolase) increased the likelihood that nuclear extracts used in the experiments were free of cytosolic contaminants. However, it should be noted that results based on an affinity chromatography approach indicate only a tendency of proteins to associate under physiological-like conditions and thus, they may lead to higher number of false positives.

\section{Discussion}

Recent studies have revealed that a regulatory enzyme of gluconeogenesis-FBPase-is localized in nuclei of proliferating cells and that nuclear transport of the enzyme is regulated by extracellular stimuli (Gizak et al. 2005, 2006, 2009; Mamczur et al. 2010). In contrast to dividing cells, FBPase is absent in nuclei of terminally differentiated cells (Gizak et al. 2006; Mamczur et al. 2010). These findings point to FBPase as a protein potentially involved in cell cycle regulation and/or progression.

Here, we present evidence that in the KLN-205 cells, in SCC cells and in HL-1 cardiomyocytes, FBPase accumulates in the nuclei during $\mathrm{S}$ and $\mathrm{G} 2$ phases of the cell cycle. Furthermore, we demonstrate that serum starvation-provoked cell cycle exit results not only in cytoplasmic retention of FBPase but also in significant changes in expression of the enzyme. 

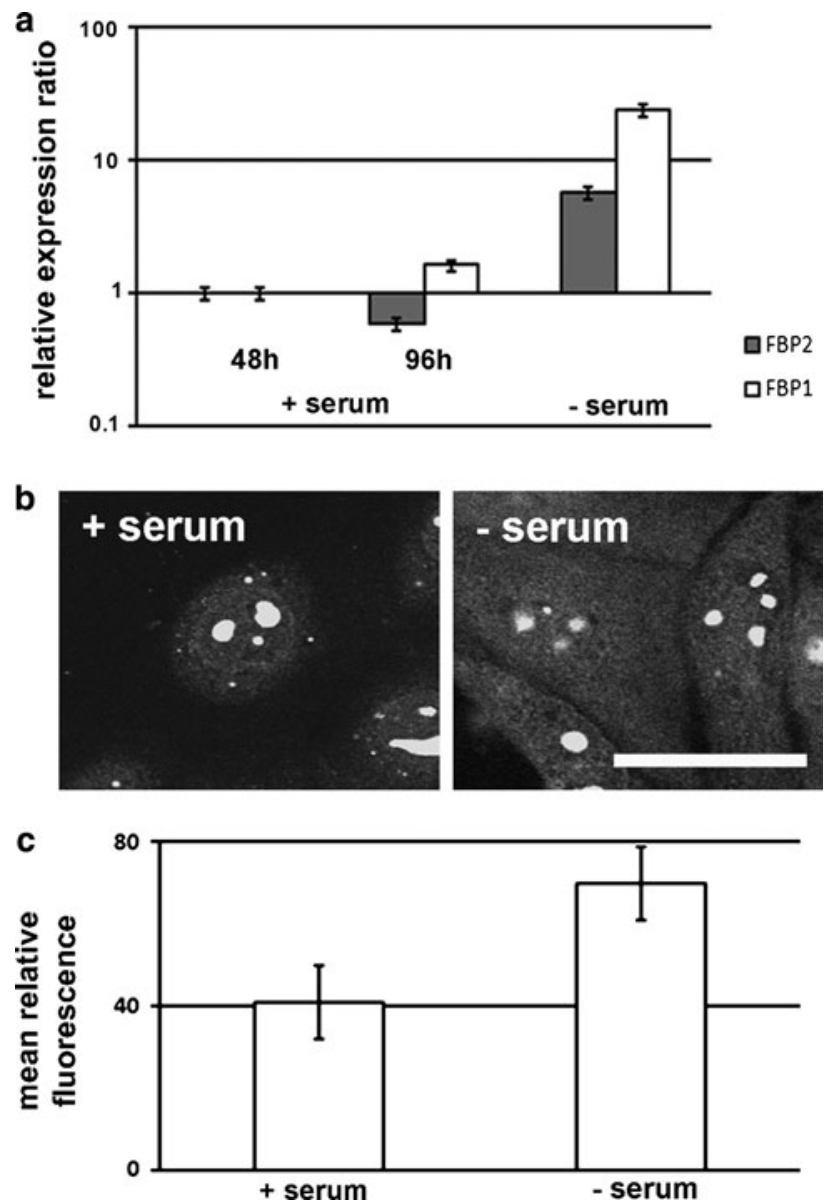

Fig. 6 Correlation between expression of FBPase isozymes and the KLN-205 cell culture growth. a qPCR analysis of the expression versus time of the culture growth. b FISH analysis of mRNA for FBP2 in quiescent cells (-serum) in comparison with the cells cultured in the presence of serum (+serum). Scale bar $25 \mu \mathrm{m}$. c The measurement of FISH signal from mRNA of FBPase in the cell culture with and without serum

An increasing confluence of cell culture results in the reduction of a cell's proliferative activity and correlates with an increased number of cells in G0 and G1 phases (Khammanit et al. 2008; Hayes et al. 2005). Similarly, an increasing number of quiescent cells (commonly referred to as G0 cells) may be achieved by serum withdrawal from the culture medium (Khammanit et al. 2008; Hayes et al. 2005). In studying the subcellular localization of FBPase, we observed that increasing the proportion of G1 and/or G0 cells during cell culture growth results in a decrease of FBPase in cell nuclei. Furthermore, we also found that FBPase-related fluorescence and activity of the enzyme are strongly reduced in confluent (thus, presumably non-proliferating) cell cultures and in serum-starved cells as compared with proliferating cells. This reduction in fluorescence and enzyme activity suggests that FBPase is not only a gluconeogenic enzyme, but is also involved in cell proliferation.
The reduced amount of FBPase in G0 and G1 cells contradicts some recent studies showing that the mRNA level for FBPase isozymes is higher in non-proliferating cells than in tumors (Liu et al. 2010). However, in contrast to the amount of the protein, we found the level of FBPase mRNA is several times higher in the G0-like phase cells, than in proliferating cells. Thus, there is no discrepancy between our findings and those of the Bigl and Liu (Bigl et al. 2008; Liu et al. 2010) in terms of mRNA expression. However, our findings raise questions about the physiological meaning of FBPase mRNA accumulation in the G0 phase and the mechanisms controlling FBPase mRNA translation.

A careful examination of the subcellular distribution of FBPase in relation to the cell cycle phases revealed that the enzyme localizes in nuclei of the KLN-205 cells positive for CycA and CycB1. Since the cyclins are markers of S and G2 phase cells (Dobashi et al. 2003; Soria et al. 2000; Pagano et al. 1992), the nuclear coexistence of the cyclins and FBPase supports our hypothesis that the nuclear function of FBPase is related to some cell cycle events.

In contrast to the KLN-205 cells, nuclear import of FBPase in the HL-1 cardiomyocytes is regulated by norepinephrine (Gizak et al. 2009). FBPase localizes in the nuclei of about $10 \%$ of HL-1 cells in the absence of NE, whereas upon NE stimulation around $90 \%$ of the cells display nuclear localization of the enzyme. Nevertheless, a significant elevation in nuclear FBPase does not correlate with an equivalent increase in the rate of the cells' proliferation (Gizak et al. 2009). This lack of a strong correlation may suggest that nuclear FBPase is not indispensable for the HL-1 cell cycle progression. However, in contrast to cells undergoing a canonical cell cycle, the HL-1 cells ablate the G1/S checkpoint by continuously overexpressing LEK1 proteins, which interact with retinoblastoma and liberate the E2F transcription factor to promote continued mitosis (Dees et al. 2005). Therefore, a weak correlation between nuclear localization of FBPase and the rate of the HL-1 proliferation might be the result of an ability of the HL-1 cells to divide independently of the G1/S checkpoint machinery.

Aphidicolin-induced cell cycle arrest in the early $S$ phase results in strong nuclear accumulation of FBPase, both in the HL-1 and in the KLN-205 cell lines. APC blocks cell cycle progression by inhibiting DNA polymerase activity (Pedrali-Noy et al. 1982) and S phase continuation without affecting the G1/S checkpoint. Thus, nuclear accumulation of FBPase in the APC-synchronized cells indicates that the enzyme is transported into the nucleus prior to the beginning of DNA replication, at the G1/S boundary of the cell cycle.

Furthermore, concanavalin A treatment of cells results in cytoplasmic retention of FBPase. ConA arrests the cell 
Fig. 7 The dependence of expression of mRNA for muscle FBPase in the KLN-205 cells on the cell culture density and its correlation to the expression of S/G2 phases marker (CycA). a FISH signals related to mRNA for FBP2 observed in various time of the cell culture growth. Scale bar $25 \mu \mathrm{m}$.

b Quantification of FISH signals as a function of cell density. c Double fluorescent labeling of the KLN-205 cells showing the correlation between the expression of mRNA for FBPase (FISH method) and the amount of CycA (immunofluorescent staining). Arrows indicate the KLN-205 cells with high amount of both CycA and mRNA for FBPase. Scale bar $40 \mu \mathrm{m}$
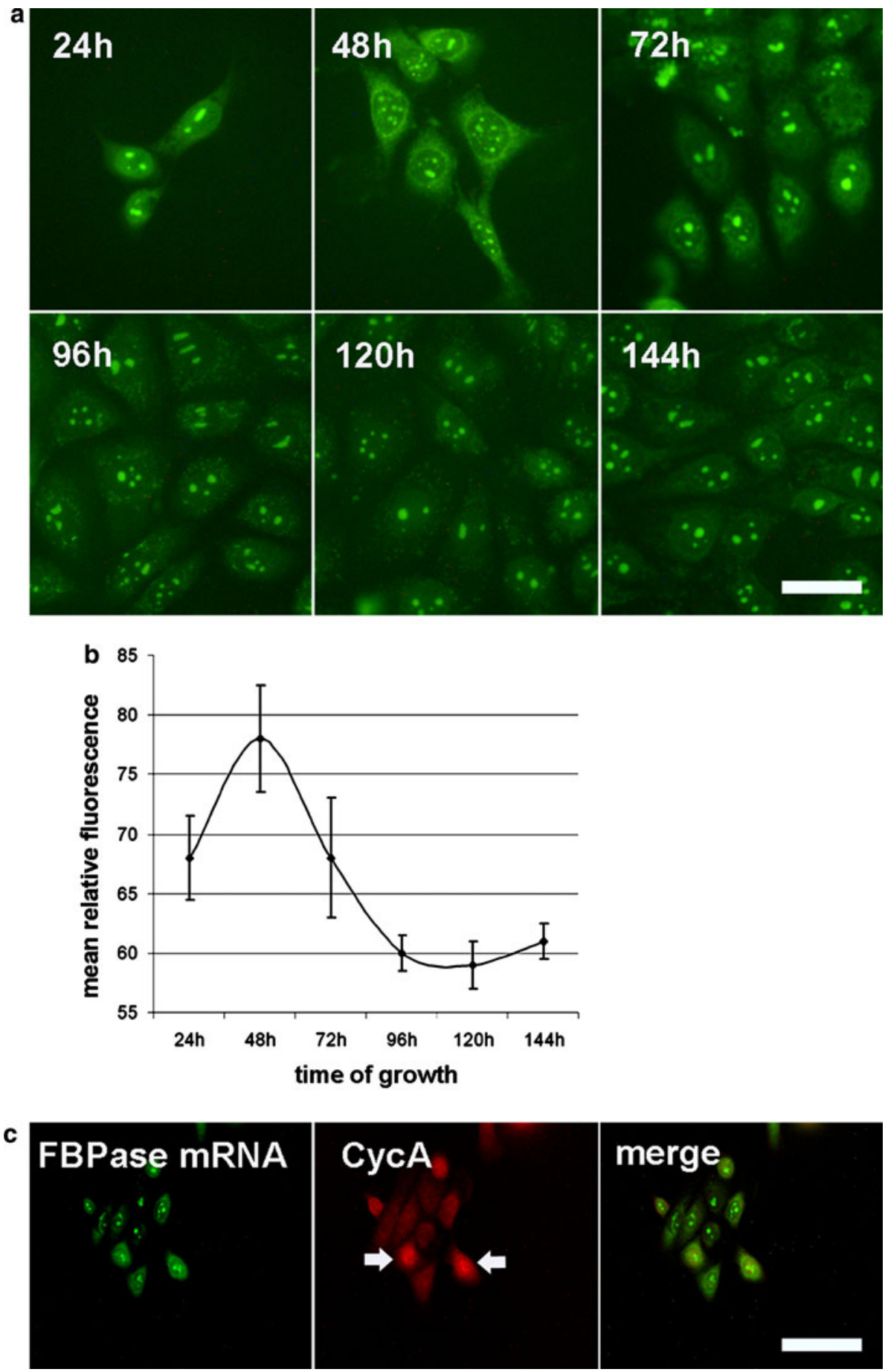

cycle at the late $\mathrm{G} 1$ phase decreasing the amount of $\mathrm{CycD}$ and $\mathrm{CycE}$ and hence, inhibiting the G1/S checkpoint progression (Desrivières et al. 1997). The effect of ConA is thus in line with our assumption that FBPase is transported into the nucleus in the late G1 phase.

To check if nuclear localization of FBPase in the S and G2 phase cells is not limited to cell cultures, we analyzed the expression and subcellular localization of the enzyme and the cyclins in human SCC sections. The absence of nuclear FBPase in CycD1-positive cells and co-accumulation of FBPase and S/G2 phases-related cyclins (A and B1) in the cells' nuclei support the hypothesis that FBPase is engaged in $\mathrm{S}$ and $\mathrm{G} 2$ phase events.

FBPase localizes in about half of CycE positive cells' nuclei of the KLN-205 cells. However, in the human SCC, we could not find any nuclei simultaneously positive for FBPase and CycE. This may be due to the slight differences in the time frame of expression and nuclear 
Fig. 8 The effect of serum starvation on FBPase localization and on proliferative activity of the KLN-205 cells.

The influence of serum withdrawal on:

a immunostaining for

proliferation marker (Ki-67) and the mitotic index; $\mathbf{b}$ the amount of FBPase in the KLN-205 cells. To exclude the effect of the culture confluence, both experiments were performed at comparable cell culture density. c The results of serum readdition on $\mathrm{Ki}-67$

immunolabeling.

d Accumulation of FBPase and $\mathrm{CycA}$ in cell nuclei during serum-stimulated cell cycle entrance. All quantitative data are presented as a mean \pm SD a

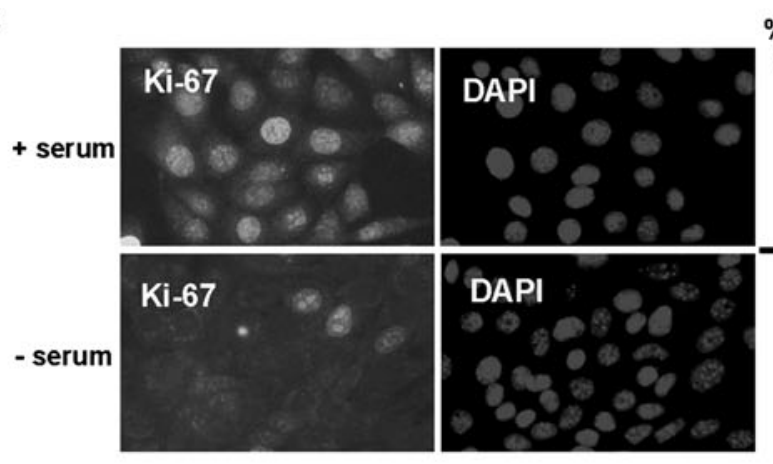

b



C
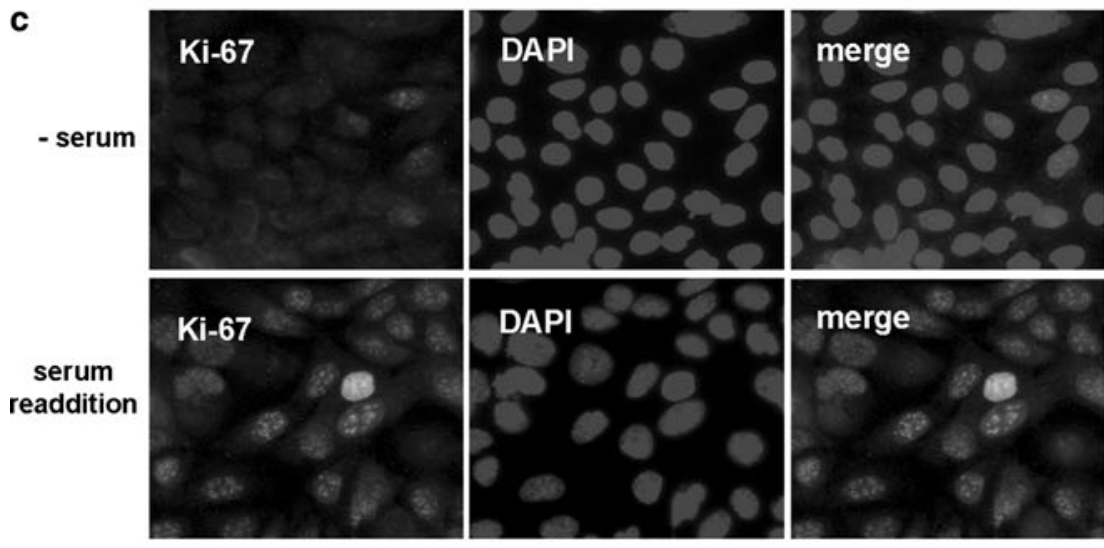

d
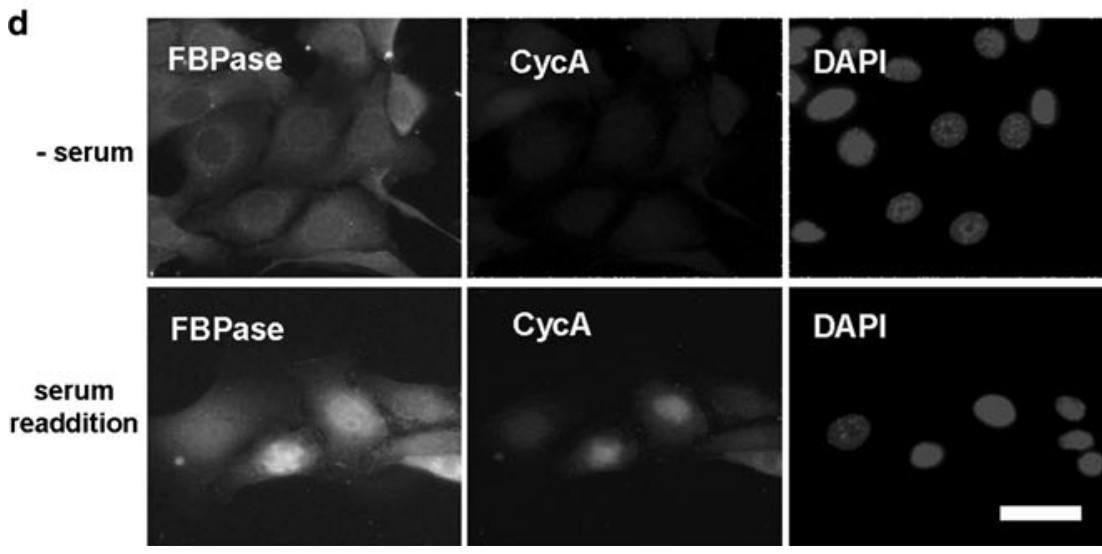

$\%$ of max. mitotic $\mathrm{Ki}-67$ density index labeling

\begin{tabular}{c|c|c}
11 & 4.38 & 97 \\
\pm 3 & \pm 0.27 & \pm 0.9 \\
& & \\
\hline 17 & 0.59 & 13 \\
\pm 2 & \pm 0.32 & \pm 2.1
\end{tabular}

Mean FBPase-related fluorescence

21

$\pm 9$

2.1

\section{.}


Fig. 9 The effect of aphidicolin (APC) and norepinephrine (NE) on FBPase and CycA

localization in the KLN-205 and HL-1 cell lines. Nuclear accumulation of FBPase in APC-treated the KLN-205 and HL-1 cells. Nuclear localization of FBPase in the APC-treated HL-1 cells is independent to NE stimulation. Scale bar $20 \mu \mathrm{m}$

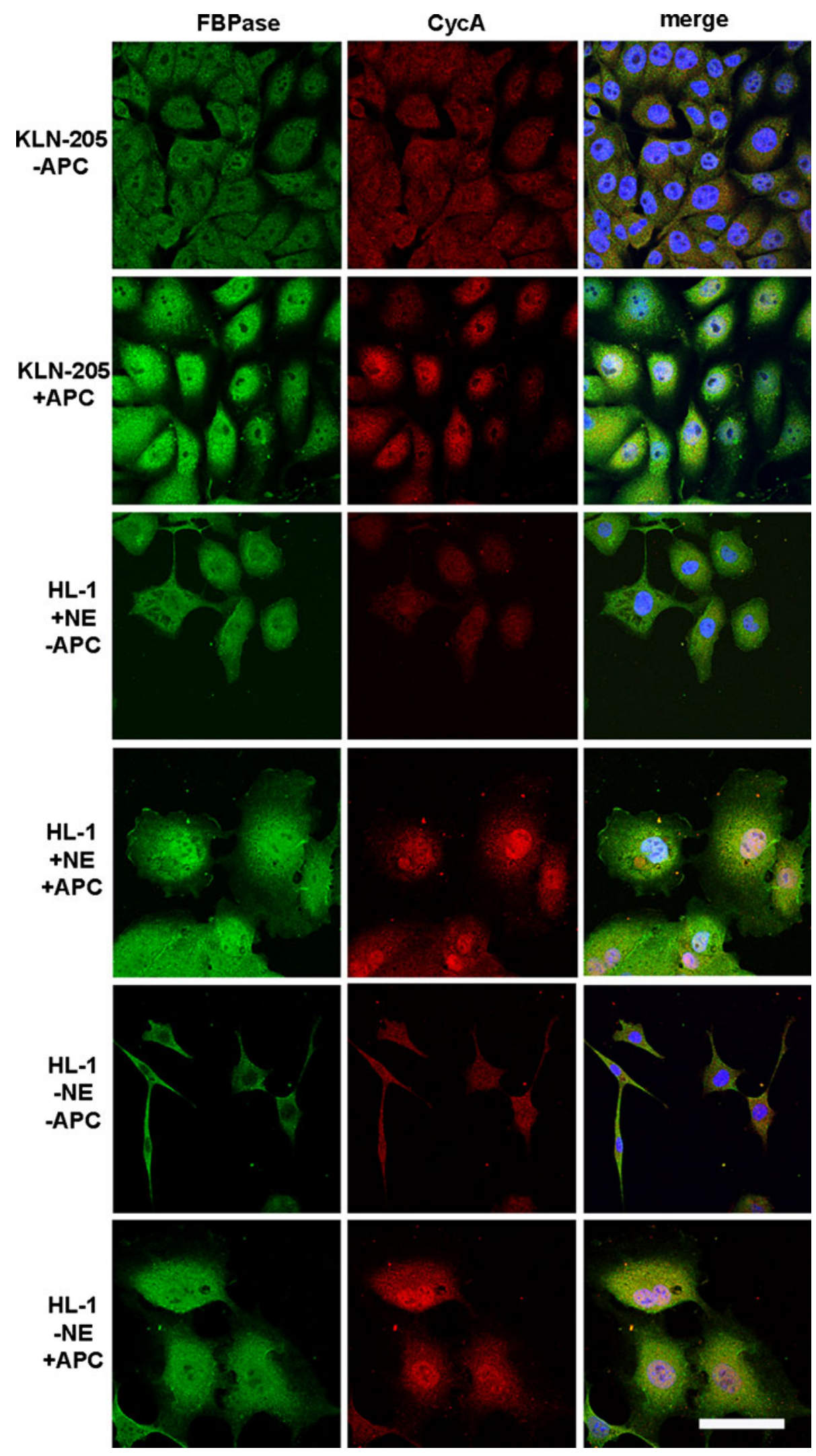


Fig. 10 The effect of concanavalin A on FBPase localization in the KLN-205 cells. a The lack of nuclear accumulation of FBPase in ConA-treated cells. Nuclei were counterstained with DAPI. Scale bar $50 \mu \mathrm{m}$. b A dosedependent effect of ConA on nuclear localization of FBPase. Each value represents the mean and standard deviation of at least three independent experiments
Table 3 The KLN-205 histone proteins interacting with muscle FBPase identified by mass spectrometry
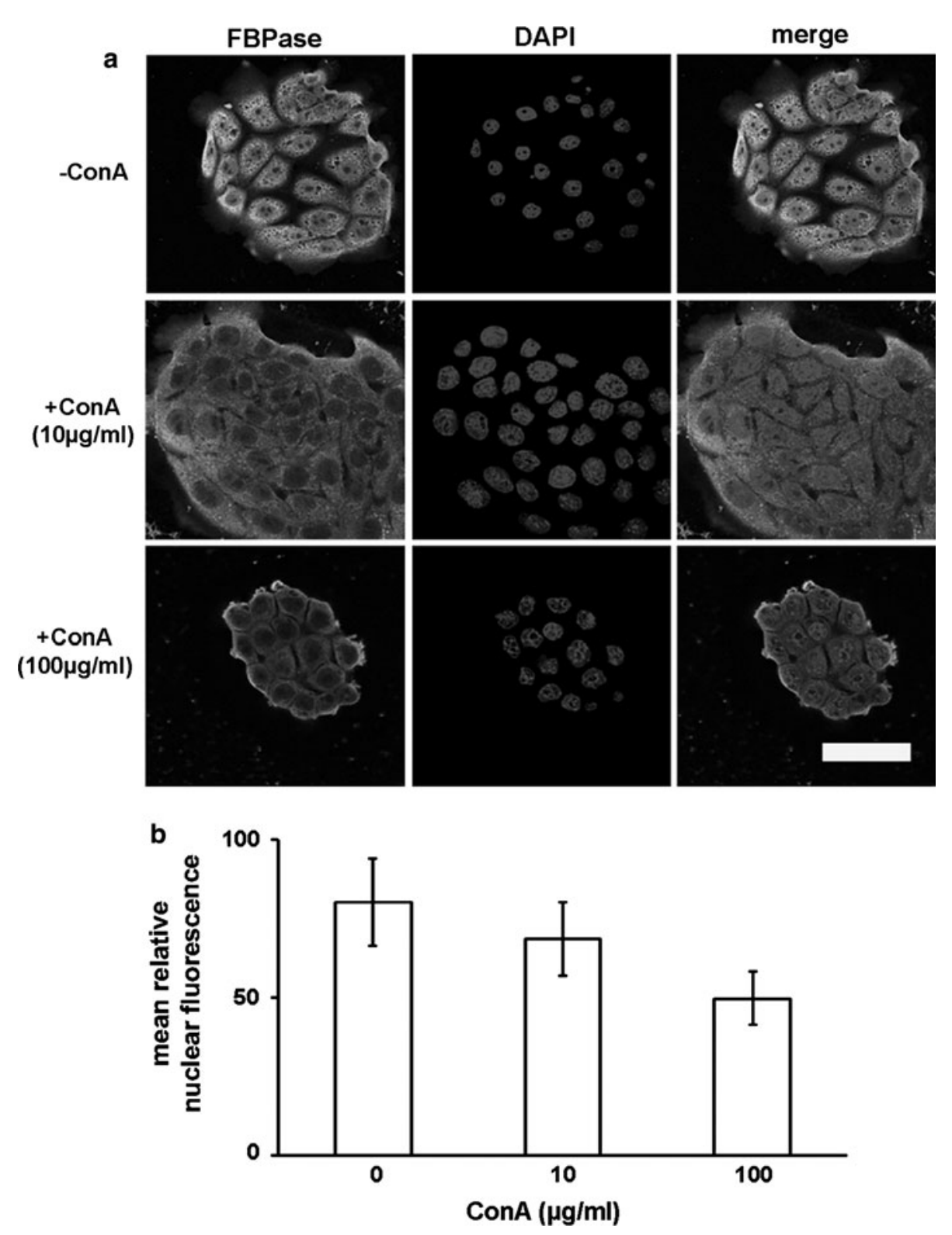

\begin{tabular}{llllc}
\hline Histone type & Accession numbers & MW $(\mathrm{kDa})$ & Sequence coverage $(\%)$ & Protein score \\
\hline Histone H1 & UniProt ID: P15864 & 21.2 & 31 & 473 \\
& UniProt ID: P43274 & 21.9 & 29 & 463 \\
& UniProt ID: P43277 & 22 & 28 & 416 \\
& UniProt ID: P10922 & 23 & 23 & 364 \\
Histone H2A & UniProt ID: Q6GSS7 & 14 & 49 & 861 \\
& UniProt ID: Q64523 & 14 & 49 & 861 \\
& UniProt ID: P27661 & 14 & 27 & 893 \\
& UniProt ID: P0C0S6 & 13.5 & 53 & 543 \\
Histone H2B & UniProt ID: Q64522 & 14 & 46 & 903 \\
Histone H4 & UniProt ID: Q6ZWY9 & 14 & 44 & 1,012 \\
& UniProt ID: P62806 & 11.3 & 50 & 939
\end{tabular}


Table 4 The KLN-205 non-histone nuclear proteins interacting with muscle FBPase identified by mass spectrometry

\begin{tabular}{|c|c|c|c|c|c|}
\hline Protein type & Protein & $\begin{array}{l}\text { Accession } \\
\text { numbers }\end{array}$ & $\begin{array}{l}\mathrm{MW} \\
(\mathrm{kDa})\end{array}$ & $\begin{array}{l}\text { Sequence } \\
\text { coverage }(\%)\end{array}$ & $\begin{array}{l}\text { Protein } \\
\text { score }\end{array}$ \\
\hline \multirow[t]{4}{*}{ RNPs } & Heterogeneous nuclear ribonucleoprotein A3 (hnRNP A3) ${ }^{\mathrm{a}}$ & UniProt ID: Q8BG05 & 39.6 & 16 & 1,421 \\
\hline & Heterogeneous nuclear ribonucleoproteins A2/B1 (hnRNP A2/B1) ${ }^{\mathrm{a}}$ & UniProt ID: O88569 & 37.4 & 32 & 944 \\
\hline & Heterogeneous nuclear ribonucleoprotein $\mathrm{I}^{\mathrm{a}}$ & UniProt ID: P17225 & 56.4 & 49 & 726 \\
\hline & H/ACA ribonucleoprotein complex subunit 4 & UniProt ID: Q9ESX5 & 57.5 & 15 & 436 \\
\hline \multirow[t]{2}{*}{ Helicases } & Nucleolar RNA helicase 2 & UniProt ID: Q9JIK5 & 93.9 & 28 & 729 \\
\hline & ATP-dependent RNA helicase $\mathrm{A}^{\mathrm{a}}$ & UniProt ID: O70133 & 149 & 27 & 974 \\
\hline \multirow[t]{2}{*}{ Thymopoietins } & Thymopoietin isoforms alpha/zeta ${ }^{a}$ & UniProt ID: Q61033 & 75 & 31 & 655 \\
\hline & Thymopoietin isoforms beta/delta/epsilon/gamma & UniProt ID: Q61029 & 50 & 41 & 631 \\
\hline \multirow[t]{7}{*}{ Others } & Lamin-A/C ${ }^{a}$ & UniProt ID: P48678 & 74 & 53 & 1,252 \\
\hline & Nucleolar protein $56^{\mathrm{a}}$ & UniProt ID: Q9D6Z1 & 64.4 & 36 & 764 \\
\hline & Alpha-II spectrin & UniProt ID: P16546 & 284.5 & 21 & 1,449 \\
\hline & Nucleophosmin & UniProt ID: Q61937 & 32.5 & 30 & 1,887 \\
\hline & Myb-binding protein $1 \mathrm{~A}^{\mathrm{a}}$ & UniProt ID: Q7TPV4 & 152 & 32 & 3,588 \\
\hline & Nucleolin $^{\mathrm{a}}$ & UniProt ID: P09405 & 76.6 & 32 & 2,864 \\
\hline & THO complex subunit 4 & UniProt ID: O08583 & 27 & 36 & 701 \\
\hline
\end{tabular}

a Interchromatin granule clusters (IGC) proteins (Rappsilber et al. 2002; Saitoh et al. 2004)

localization of CycE between the KLN-205 cells and the SCC. In contrast to the SCC, CycE partially coexists with an $\mathrm{S}$ phase marker, CycA, in nuclei of the KLN-205 cells (data not shown). Thus, the nuclear localization of $\mathrm{CycE}$ both in G1 and in S phase of the KLN-205 cells explains only partial co-localization of FBPase and the cyclin.

Searching for FBPase binding partners in the nucleus, we found that the enzyme could interact with several proteins participating in the formation of interchromatin granule clusters (IGC), the structures involved in mRNA processing (Saitoh et al. 2004). Several of the IGC components interacting with FBPase, e.g., Myb-binding protein 1A, RNPs and helicases (Gewirtz et al. 1989; Zhang et al. 2004; He et al. 2005), are known to operate in a cell cycledependent manner. Thus, it cannot be excluded that FBPase participates in cell cycle-dependent mRNA processing. However, the most interesting possibility in the context of our findings and cell cycle regulation is that FBPase may interact with components of the Myb-binding protein 1A/nucleolin/nucleophosmin complex (MNN complex). The MNN complex negatively regulates the G1/ $\mathrm{S}$ transition by associating with several transcription factors (e.g. c-Myb and NF-kappaB) (Yamauchi et al. 2008). Therefore, an attractive hypothesis is that nuclear FBPase affects the cell cycle by modulating the liberation of some of the transcription factors from the MNN complex. Because the Myb family proteins also contribute directly to the G2/M transition (Nakata et al. 2007) the ability of FBPase to associate with MNN may explain nuclear localization of the enzyme during the S and G2 stages.

Among nuclear proteins interacting with FBPase, we also found almost all members of the canonical histones.
This is in line with our unpublished findings that FBPase interacts with histone family proteins in cardiomiocytes (Gizak et al. unpublished data) and participates in some, yet unknown, nucleosome-related processes and requires further studies.

Taken together, our study demonstrates that in human squamous cell lung cancer and the immortalized cell linesHL-1 and KLN-205, FBPase accumulates in cell nuclei during the $\mathrm{S}$ and $\mathrm{G} 2$ phase. Nuclear FBPase interacts with the histone family members and with several proteins involved in cell cycle regulation and RNA processing.

Further study of cells that overexpress muscle FBPase mutants lacking enzymatic activity and/or a nuclear localization signal may help to determine the exact role of the enzyme in cell cycle regulation.

Acknowledgments This work was supported by Polish Ministry of Science and Higher Education Grant, \#N N401 376139. The authors thank Dr. Agnieszka Gizak for help in improving the manuscript.

Open Access This article is distributed under the terms of the Creative Commons Attribution Noncommercial License which permits any noncommercial use, distribution, and reproduction in any medium, provided the original author(s) and source are credited.

\section{References}

Al-Robaiy S, Eschrich K (1999) Rat muscle fructose-1, 6-bisphosphatase: cloning of the cDNA, expression of the recombinant enzyme, and expression analysis in different tissues. Biol Chem 380:1079-1085 
Bankfalvi A, Navabi H, Bier B, Böcker W, Jasani B, Schmid KW (1994) Wet autoclave pretreatment for antigen retrieval in diagnostic immunohistochemistry. J Pathol 174:223-228

Bigl M, Jandrig B, Horn LC, Eschrich K (2008) Aberrant methylation of human L- and M-fructose 1, 6-bisphosphatase genes in cancer. Biochem Biophys Res Commun 377:720-724

Chomczynski P, Sacchi N (1987) Single-step method of RNA isolation by acid guanidinium thiocyanate-phenol-chloroform extraction. Anal Biochem 162:156-159

Claycomb WC, Lanson NA Jr, Stallworth BS, Egeland DB, Delcarpio JB, Bahinski A, Izzo NJ Jr (1998) HL-1 cells: a cardiac muscle cell line that contracts and retains phenotypic characteristics of the adult cardiomyocyte. Proc Natl Acad Sci USA 95:2979-2984

Dees E, Robertson JB, Ashe M, Pabón-Peña LM, Bader D, Goodwin RL (2005) LEK1 protein expression in normal and dysregulated cardiomyocyte mitosis. Anat Rec A Discov Mol Cell Evol Biol 286:823-832

Desrivières S, Volarević S, Merćep L, Ferrari S (1997) Evidence for different mechanisms of growth inhibition of T-cell lymphoma by phorbol esters and concanavalin A. J Biol Chem 272:24702476

Dobashi Y, Jiang SX, Shoji M, Morinaga S, Kameya T (2003) Diversity in expression and prognostic significance of G1/S cyclins in human primary lung carcinomas. J Pathol 199:208-220

Gewirtz AM, Anfossi G, Venturelli D, Valpreda S, Sims R, Calabretta B (1989) G1/S transition in normal human T-lymphocytes requires the nuclear protein encoded by c-myb. Science 245:180-183

Gizak A, Dzugaj A (2003) FBPase is in the nuclei of cardiomyocytes. FEBS Lett 539:51-55

Gizak A, Rakus D, Dzugaj A (2005) Nuclear localization of fructose 1, 6-bisphosphatase in smooth muscle cells. J Mol Histol 36:243-248

Gizak A, Wrobel E, Moraczewski J, Dzugaj A (2006) Changes in subcellular localization of fructose 1, 6-bisphosphatase during differentiation of isolated muscle satellite cells. FEBS Lett 580:4042-4046

Gizak A, Zarzycki M, Rakus D (2009) Nuclear targeting of FBPase in HL- 1 cells is controlled by beta- 1 adrenergic receptor-activated Gs protein signaling cascade. Biochim Biophys Acta 1793:871-877

Gleeson TT (1996) Post-exercise lactate metabolism: a comparative review of sites, pathways, and regulation. Annu Rev Physiol $58: 565-581$

Gomori G (1943) Calcification and phosphatase. Am J Pathol 19:197-209

Hayes O, Ramos B, Rodríguez LL, Aguilar A, Badía T, Castro FO (2005) Cell confluency is as efficient as serum starvation for inducing arrest in the G0/G1 phase of the cell cycle in granulosa and fibroblast cells of cattle. Anim Reprod Sci 87:181-192

He Y, Brown MA, Rothnagel JA, Saunders NA, Smith R (2005) Roles of heterogeneous nuclear ribonucleoproteins A and B in cell proliferation. J Cell Sci 118:3173-3183

Khammanit R, Chantakru S, Kitiyanant Y, Saikhun J (2008) Effect of serum starvation and chemical inhibitors on cell cycle synchronization of canine dermal fibroblasts. Theriogenology 70:27-34

Kowalski W, Gizak A, Rakus D (2009) Phosphoglycerate mutase in mammalian striated muscles: subcellular localization and binding partners. FEBS Lett 583:1841-1845

Liu X, Wang X, Zhang J, Lam EK, Shin VY, Cheng AS, Yu J, Chan FK, Sung JJ, Jin HC (2010) Warburg effect revisited: an epigenetic link between glycolysis and gastric carcinogenesis. Oncogene 29:442-450
Mallucci L, Dunn M, Wells V, Delia D (1980) A cell cycle study of the effects of Con A on synchronized mouse embryo fibroblasts: arrest at two specific stages of the cycle and dissociation between uptake of thymidine and DNA synthesis. J Cell Sci 46:353-363

Mamczur P, Mazurek J, Rakus D (2010) Ubiquitous presence of gluconeogenic regulatory enzyme, fructose-1, 6-bisphosphatase, within layers of rat retina. Cell Tissue Res 341:213-221

Nakata Y, Shetzline S, Sakashita C, Kalota A, Rallapalli R, Rudnick SI, Zhang Y, Emerson SG, Gewirtz AM (2007) c-Myb contributes to $\mathrm{G} 2 / \mathrm{M}$ cell cycle transition in human hematopoietic cells by direct regulation of cyclin B1 expression. Mol Cell Biol 27:2048-2058

Pagano M, Pepperkok R, Verde F, Ansorge W, Draetta G (1992) Cyclin $\mathrm{A}$ is required at two points in the human cell cycle. EMBO J 11:961-971

Parnas D, Linial M (1998) Highly sensitive ELISA-based assay for quantifying protein levels in neuronal cultures. Brain Res Brain Res Protoc 2:333-338

Pedrali-Noy G, Belvedere M, Crepaldi T, Focher F, Spadari S (1982) Inhibition of DNA replication and growth of several human and murine neoplastic cells by aphidicolin without detectable effect upon synthesis of immunoglobulins and HLA antigens. Cancer Res 42:3810-3813

Pfaffl MW (2001) A new mathematical model for relative quantification in real-time RT-PCR. Nucleic Acids Res 29:2002-2007

Rakus D, Dzugaj A (2000) Muscle aldolase decreases muscle FBPase sensitivity toward AMP inhibition. Biochem Biophys Res Commun 275:611-616

Rappsilber J, Ryder U, Lamond AI, Mann M (2002) Large-scale proteomic analysis of the human spliceosome. Genome Res 12:1231-1245

Saitoh N, Spahr CS, Patterson SD, Bubulya P, Neuwald AF, Spector DL (2004) Proteomic analysis of interchromatin granule clusters. Mol Biol Cell 15:3876-3890

Seo BB, Wang J, Flotte TR, Yagi T, Matsuno-Yagi A (2000) Use of the NADH-quinone oxidoreductase (NDI1) gene of Saccharomyces cerevisiae as a possible cure for complex I defects in human cells. J Biol Chem 275:37774-37778

Soria JC, Jang SJ, Khuri FR, Hassan K, Liu D, Hong WK, Mao L (2000) Overexpression of cyclin B1 in early-stage non-small cell lung cancer and its clinical implication. Cancer Res 60:40004004

Spitzer MS, Wallenfels-Thilo B, Sierra A, Yoeruek E, Peters S, Henke-Fahle S, Bartz-Schmidt KU, Szurman P, Tuebingen Bevacizumab Study Group (2006) Antiproliferative and cytotoxic properties of bevacizumab on different ocular cells. $\mathrm{Br} \mathrm{J}$ Ophthalmol 90:1316-1321

Tejwani GA (1983) Regulation of fructose-bisphosphatase activity. Adv Enzymol Relat Areas Mol Biol 54:121-194

Tillmann H, Bernhard D, Eschrich K (2002) Fructose-1, 6-bisphosphatase genes in animals. Gene 291:57-66

White SM, Constantin PE, Claycomb WC (2004) Cardiac physiology at the cellular level: use of cultured HL-1 cardiomyocytes for studies of cardiac muscle cell structure and function. Am J Physiol Heart Circ Physiol 286:H823-H829

Yamauchi T, Keough RA, Gonda TJ, Ishii S (2008) Ribosomal stress induces processing of Mybbpla and its translocation from the nucleolus to the nucleoplasm. Genes Cells 13:27-39

Zhang S, Köhler C, Hemmerich P, Grosse F (2004) Nuclear DNA helicase II (RNA helicase A) binds to an F-actin containing shell that surrounds the nucleolus. Exp Cell Res 293:248-258 